\title{
A scorecard for osteoporosis in Canada and seven Canadian provinces
}

\author{
D.L. Kendler ${ }^{1}$ • J.D. Adachi ${ }^{2}$ • J.P. Brown ${ }^{3}$ - A.G. Juby ${ }^{4}$ C.S. Kovacs ${ }^{5}$ - C. Duperrouzel ${ }^{6} \cdot$ R.K. McTavish ${ }^{6} \cdot$ C. Cameron ${ }^{6}$. \\ L. Slatkovska ${ }^{7}$ N. Burke ${ }^{7}$
}

Received: 4 March 2020 / Accepted: 15 July 2020 / Published online: 25 July 2020

(C) The Author(s) 2020

\begin{abstract}
Summary The scorecard evaluates the burden and management of osteoporosis in Canada and how care pathways differ across Canadian provinces. The results showed there are inequities in patients' access to diagnosis, treatment, and post-fracture care programs in Canada. Interventions are needed to close the osteoporosis treatment gap and minimize these inequities.

Introduction The purpose of this study was to develop a visual scorecard that assesses the burden of osteoporosis and its management within Canada and seven Canadian provinces.

Methods We adapted the Scorecard for Osteoporosis in Europe (SCOPE) to score osteoporosis indicators for Canada and seven provinces (British Columbia, Alberta, Saskatchewan, Ontario, Quebec, New Brunswick, and Newfoundland). We obtained data from a comprehensive literature review and interviews with osteoporosis experts. We scored 20 elements across four domains: burden of disease, policy framework, service provision, and service uptake. Each element was scored as red, yellow, or green, indicating high, intermediate, or low risk, respectively. Elements with insufficient data were scored black.

Results Canada performed well on several elements of osteoporosis care, including high uptake of risk assessment algorithms and minimal wait times for hip fracture surgery. However, there were no established fracture registries, and reporting on individuals with high fracture risk who remain untreated was limited. Furthermore, osteoporosis was not an official health priority in most provinces. Government-backed action plans and other osteoporosis initiatives were primarily confined to Ontario and Alberta. Several provinces (Saskatchewan, New Brunswick, Newfoundland) did not have any registered fracture liaison service (FLS) programs. Access to diagnosis and treatment was also inconsistent and reimbursement policies did not align with clinical guidelines.

Conclusion Government-backed action plans are needed to address provincial inequities in patients' access to diagnosis, treatment, and FLS programs in Canada. Further characterization of the treatment gap and the establishment of fracture registries are critical next steps in providing high-quality osteoporosis care.
\end{abstract}

Keywords Canada $\cdot$ Healthcare quality $\cdot$ Osteoporosis $\cdot$ Scorecard

Electronic supplementary material The online version of this article (https://doi.org/10.1007/s00198-020-05554-2) contains supplementary material, which is available to authorized users.

N. Burke

nburke02@amgen.com

1 The University of British Columbia, Vancouver, British Columbia, Canada

2 McMaster University, Hamilton, Ontario, Canada

3 Laval University, Quebec City, Quebec, Canada
4 University of Alberta, Edmonton, Alberta, Canada

5 Memorial University, St. John's, Newfoundland, Canada

EVERSANA, Burlington, Ontario, Canada

7 Amgen Inc., Mississauga, Ontario, Canada 


\section{Introduction}

Osteoporosis is a skeletal disorder characterized by low bone mineral density (BMD) and increased risk of fragility fracture [1]. BMD decreases with age and declines more rapidly during menopause [1]. In Canada, an estimated $10 \%$ of all adults aged $>40$ years and $21 \%$ of post-menopausal women are osteoporotic $[2,3]$. The proportion of Canadians aged $\geq 65$ years is expected to increase rapidly over the next decade and will comprise up to $25 \%$ of the population in 2036 - up from $14 \%$ in 2011 [4]. As Canada's population ages, the number of osteoporotic fractures is predicted to increase [5].

Hip fractures are often considered the most serious type of fracture because they frequently result in a loss of independence and increased mortality [6]. An estimated $22 \%$ of Canadian women and $33 \%$ of Canadian men die in the first year following a hip fracture $[6,7]$. Moreover, patients with an index fracture are more likely to sustain subsequent fractures, which account for $40 \%$ of all osteoporotic fractures in Canada [8]. In 2014, the annual cost of osteoporosis in Canada was estimated to exceed 4.6 billion CAD [9, 10]. Increased screening of high-risk individuals and treatment initiation may reduce the rate of fractures and lead to significant cost savings.

Osteoporosis is a largely preventable disease, yet hundreds of thousands of Canadians with osteoporosis still go undetected and untreated [11]. In 2008, Osteoporosis Canada released a report card on the state of osteoporosis care in Canada showing inadequate access to BMD testing across the Canadian provinces/territories and assigned mixed grades for access to medication [12]. Furthermore, results showed that osteoporosis initiatives had only been established in a few Canadian provinces at the time the report card was conducted [12].

A more extensive analysis was conducted for the 27 countries of the European Union (EU) in the 2013 Scorecard for Osteoporosis in Europe (SCOPE) [13]. The SCOPE framework has since been applied to an additional four Latin American countries [14]. Our objective was to create an osteoporosis scorecard for Canada that also applied the SCOPE framework. We used the SCOPE framework over the report card format because it has been peer-reviewed, provides a broader basis for the assessment of care, and allows Canada to be compared against other countries. In addition to the national-level scorecard, we sought to expand the SCOPE framework to Canadian provinces in order to identify regional variations in osteoporosis care. The consideration of regional differences was important because, although Canada has a universal publicly funded healthcare system, the delivery of healthcare is primarily the responsibility of the provinces and territories.

\section{Methods}

We aimed to develop a scorecard for Canada and the Canadian provinces/territories. We replicated the scoring criteria from SCOPE, which scored the 27 EU countries across four domains: (1) burden of disease, (2) policy framework, (3) service provision, and (4) service uptake [13]. The domains were divided into a total of 20 scorecard elements addressing different osteoporosis indicators: a red score indicated high risk, a yellow score indicated intermediate risk, and a green score indicated low risk. In general, yellow and red scores may be interpreted as warning signals, representing increased risk of fractures or inadequate care. Elements were scored as black if no information was available.

We informed our scorecard using a comprehensive literature review and interviews with leading osteoporosis specialists in Canada. The interviews were conducted by RM and CD and were pre-planned as we anticipated that there would be no publicly available, published information for some of the scorecard elements. Although we sought to include all 13 provinces/territories, we ended up selecting 7 provinces as a convenience sample based on expert availability: British Columbia, Alberta, Saskatchewan, Ontario, Quebec, New Brunswick, and Newfoundland and Labrador. Given SCOPE was designed to look at osteoporosis care at the national level, not all of the scorecard elements were amenable to provincial scoring.

Our literature review followed a pre-specified protocol that was designed and reported according to the Preferred Reporting Items for Systematic Reviews and Meta-Analysis (PRISMA) guidelines [15]. A senior medical information specialist (BS) developed and tested the search strategy (Appendix S1). On October 7, 2018, we searched Ovid MEDLINE®, including Epub Ahead of Print and In-Process and Other Non-Indexed Citations, Embase, and the Cochrane Library on Wiley. We restricted the publication date from 2010 up to the day of the search and the publication language to English.

A single reviewer $(\mathrm{AL})$ screened the title and abstracts for eligibility. Another independent reviewer (CD) then screened the eligible full-text publications for inclusion in the final review. Publications with Canadian data that addressed scorecard elements were included. Publications that only reported on individuals $<50$ years of age or non-osteoporotic fractures were excluded. A standardized template was used for data extraction.

We also conducted a gray literature search on April 16, 2018, using a modified version of the Canadian Agency for Drugs and Technologies in Health (CADTH) Grey Matters Tool [16]. The gray literature search included results published from 2010 up to the date of the search.

We interviewed one osteoporosis expert from each of the seven provinces using an adapted version of the questionnaire 
from SCOPE [13]. The experts included four rheumatologists, two endocrinologists, and one geriatrician. The osteoporosis experts provided insight into the state of osteoporosis care in Canada as well as their respective provinces.

\section{Burden of disease}

Similar to SCOPE, populating the burden of disease domain required different types of evidence from various secondary sources [13]. This is a well-recognized approach when addressing multiple complex information needs within a single analytical framework [17].

We used 2010 and 2011 publications by Leslie et al. to inform the unadjusted hip fracture rates for Canada and the provinces $[18,19]$. To ensure comparability with the fracture rates reported in SCOPE, we also extracted the hip fracture rate for Canada when age-standardized to the world population [20]. Since we did not have the necessary data to standardize the provincial rates to the world population but still needed them to be comparable to SCOPE, we applied a crude multiplier (calculated by dividing Canada's age-standardized rate $[20]$ by the unadjusted rate $[18,19])$. The hip fracture rates in women were used for scoring in SCOPE because hip fracture rates were more robust in women and available for all European countries. To maintain consistency, we also based the Canadian scoring on women.

A publication by Osteoporosis Canada estimated the number of osteoporotic fractures incurred by Canadians aged $\geq$ 50 years in 2015 [21]. To obtain the crude rate of osteoporotic fractures, we divided the number of fractures reported in the Osteoporosis Canada publication by the population of men and women aged $\geq 50$ years in 2015 from Statistics Canada [22].

We acquired the lifetime hip fracture probability among women aged 50 years from a Hopkins et al. (2012) study [23].

The licensed version of the FRAX tool analyzes large cohorts of patients at once. It is distinguished from the publicly available, web-version of the FRAX tool, which assesses one individual at a time. We did not have access to a licensed version of the FRAX tool and were therefore unable to run the simulations necessary to estimate the proportion of the population with a 10 -year probability of a major fracture $\geq$ $10 \%$. We also did not find this value reported in the literature.

We used Statistics Canada data to calculate the growth in the population aged $\geq 50$ years from 2015 to 2030 [22, 24]. We assumed that the incidence of osteoporotic fractures was constant and that the increase in fractures from 2015 to 2030 would be equal to the population growth over that time period.

\section{Policy framework}

The policy framework domain was primarily informed by the expert questionnaire. We asked the osteoporosis experts to confirm the presence of national and/or provincial fracture registries. As in SCOPE, we defined a fracture registry as a centralized database that records the annual fracture incidence within a target population and that is used for research, resource allocation, or to identify high-risk patients in need of additional care [13]. We also asked whether osteoporosis is a national health priority in Canada and used action plans found in our literature review to verify their responses. We relied on osteoporosis experts to determine whether primary care physicians or specialists are responsible for most osteoporosis cases. We referred to the Royal College of Physicians and Surgeons to determine whether osteoporosis is a recognized speciality in Canada [25]. We determined the presence of national osteoporosis support societies in Canada through listings on the International Osteoporosis Foundation's website [26]. As in SCOPE, we considered three categories of societies: (1) those primarily involved with direct patient contact, (2) societies that are patient-oriented but do not have direct patient contact, and (3) scientific societies that do not engage patients at all. Patient contact was prioritized. Therefore, if a society had the means to directly engage with patients (e.g., help line) but also performed scientific functions (e.g., physician education) it would still be scored as a patient contact society.

\section{Service provision}

To assess reimbursement policies and whether they interfere with what physicians prescribe to patients, we compared provincial public drug plan formularies (see Appendix S3) to the recommendations in the current Canadian guidelines for firstline osteoporosis treatments (i.e., denosumab, zoledronic acid, risedronate, alendronate, and raloxifene) [27].

In contrast to SCOPE, we did not have access to data from dual-energy X-ray absorptiometry (DXA) providers to evaluate the availability of operational DXA machines in Canada. Instead, we obtained the number of DXA units per million of the general population in Canada from a literature source [28]. Although the source was published prior to our date cut-off of 2010, it was located through hand-searching and included because it was the only published datapoint found on DXA availability.

We relied on osteoporosis experts to inform DXA access in their respective provinces. We validated the osteoporosis experts' responses with written reimbursement policies (see Appendix S3). We did not consider reimbursement to be a barrier to treatment as long as reimbursement criteria allowed for DXA scans every 1-3 years in appropriate individuals, as per Canada's current osteoporosis guidelines [27].

We determined the availability of a country-specific risk algorithm to assess fracture risk from the FRAX website [29]. We determined the availability of additional risk assessments (i.e., Canadian Association of Radiologists and Osteoporosis 
Canada (CAROC) risk assessment tool) by reviewing clinical practice guidelines [27].

We identified clinical practice guidelines for the assessment and treatment of osteoporosis through our literature search and queried osteoporosis experts on the use of these guidelines in clinical practice. We assessed the quality of the national guidelines using seven criteria adapted from the Appraisal of Guidelines for Research and Evaluation (AGREE) next steps consortium [30]. A positive response in each AGREE category was worth one point. We awarded up to three additional points if the guidelines included postmenopausal women, men, and/or glucocorticoid-induced osteoporosis. High-quality guidelines with an extensive scope could therefore receive a maximum of ten points.

To calculate the percentage of hospitals with a FLS program for secondary prevention of osteoporotic fractures, we extracted the number of FLS programs from the Osteoporosis Canada FLS registry, the number of hospitals in Quebec from Index Santé, and the number of hospitals in the remaining provinces from the Canadian Institute for Health Information (CIHI) [31-33]. We excluded pediatric hospitals.

We used an Osteoporosis Canada report to evaluate whether national systems were in place to systematically collect data on the quality of care provided to people with osteoporosis [34].

\section{Service uptake}

We informed the uptake of risk assessment algorithms in Canada with a Kanis et al. (2014) study, which used Google Analytics to assess the annual number of FRAX calculations by originating country [35]. We were unable to find a suitable estimate for the proportion of patients at high risk of osteoporotic fracture who remain untreated. We leveraged CIHI data to determine the average wait time for surgery following hip fracture [36].

\section{Results}

We included 41 references from our comprehensive literature review with information specific to the Canadian scorecard (see Appendix S2 for PRISMA flow diagram).

The Canadian osteoporosis scorecard is shown in Fig. 1.

\section{Burden of disease}

The age-standardized rate of hip fracture among Canadian women was 290 per 100,000 individuals corresponding to a green score [18-20]. Scores were split between the provinces, with British Columbia, Alberta, and Ontario receiving green scores and Saskatchewan, Quebec, New Brunswick, and Newfoundland receiving yellow scores [18-20].
In 2015, the crude fracture rate in Canada was approximately 16 fragility fractures per 1000 persons aged $\geq 50$ years, which was classified as a yellow score (Table 1). Most provinces also received yellow scores, indicating similar fracture rates. The exceptions were Alberta (13 fractures per 1000; green score) and Saskatchewan (22 fractures per 1000; red score) $[21,22]$.

The lifetime probability of hip fracture at age 50 years for Canadian women was $8.9 \%$, corresponding to a green score [23]. This information was not available at the provincial level.

Canada and the provinces received black scores for the FRAX risk element. The proportion of the population aged $\geq 50$ years with a 10 -year probability of a major fracture that is $10 \%$ or greater was only available for patients in the Manitoba BMD registry and for elderly men in primary care $[37,38]$. Neither of these populations were considered representative of the general population.

In Canada, the number of fragility fractures in men and women aged $\geq 50$ years was expected to increase by $24 \%$ from 211,968 fractures in 2015 to 263,810 fractures in 2030, corresponding to a green score [21, 22, 24]. Most provinces also scored green, although Ontario received a yellow score (26\% increase in fragility fractures) and Alberta scored red (39\% increase), indicating higher rates of projected population growth in individuals aged $\geq 50$ in these provinces (Table 1) $[21,22,24]$.

\section{Policy framework}

There are no national or provincial fracture registries in Canada. Good-quality hip fracture rates were available for all provinces from hospital discharge summaries collected by CIHI. The CIHI database was not considered to meet the SCOPE definition of a fracture registry because it is not designed to prospectively monitor fracture patients that may be in need of additional care [39].

In general, osteoporosis is not an official health priority in Canada. Osteoporosis is only a health priority in Alberta and Ontario. The Alberta Bone and Joint Health Institute and Alberta Health Services have developed a 5-year action plan focused on lowering fracture rates, improving osteoporosis care, and maintaining the independence of osteoporosis patients (data on file). Similarly, in 2005, the Ontario Ministry of Health launched the Ontario Osteoporosis Strategy, which focuses on fracture prevention, professional education, and patient outreach $[27,40]$.

Osteoporosis is managed primarily by general practitioners in Canada (green score). Osteoporosis experts agreed that when patients are referred to a specialist, it is usually either a rheumatologist or endocrinologist. Geriatricians, gynecologists, and internal medicine specialists play smaller roles in the management of osteoporosis. Saskatchewan and 


\begin{tabular}{|c|c|c|c|c|c|c|c|c|c|c|c|c|c|}
\hline Title & Description & & Score Criteria & & & CAN & $\mathrm{BC}$ & $A B$ & sk & ON & QC & NB & NL \\
\hline \multicolumn{14}{|c|}{ Burden of Disease } \\
\hline $\begin{array}{l}\text { Hip fracture } \\
\text { risk }\end{array}$ & $\begin{array}{l}\text { The age-standardized incidence } \\
\text { of hip fracture in women }\end{array}$ & $<300 / 100,000$ & $300-400 / 100,000$ & $>400 / 100,000$ & & & & & & & & & \\
\hline $\begin{array}{l}\text { Fracture } \\
\text { risk }\end{array}$ & $\begin{array}{l}\text { All osteoporotic fractures in men } \\
\text { and women ( } \geq 50 \mathrm{yrs})\end{array}$ & $<15 / 1,000$ & $15-20 / 1,000$ & $>20 / 1,000$ & & & & & & & & & \\
\hline $\begin{array}{l}\text { Lifetime } \\
\text { risk }\end{array}$ & $\begin{array}{l}\text { Remaining lifetime risk of hip } \\
\text { fracture (women, at } 50 \mathrm{yrs} \text { ) }\end{array}$ & $<13 \%$ & $13-18 \%$ & $>18 \%$ & & & * & * & * & * & * & * & * \\
\hline $\begin{array}{l}\text { FRAX } \\
\text { risk }\end{array}$ & $\begin{array}{l}\text { Men and women }>10 \% \text { ten-yr } \\
\text { risk of major fracture }(50-89 \mathrm{yrs})\end{array}$ & $<20 \%$ & $20-25 \%$ & $>25 \%$ & $\begin{array}{c}\text { No } \\
\text { data }\end{array}$ & & * & * & * & * & * & * & $*$ \\
\hline $\begin{array}{l}\text { Fracture } \\
\text { projections }\end{array}$ & $\begin{array}{l}\text { Increase in fracture number } \\
2015-2030 \text { ( } \geq 50 \text { yrs) }\end{array}$ & $0-25 \%$ & $26-33 \%$ & $>33 \%$ & & & & & & & & & \\
\hline \multicolumn{14}{|c|}{ Policy Framework } \\
\hline $\begin{array}{l}\text { Quality of } \\
\text { data }\end{array}$ & Data on hip fracture rates & $\begin{array}{l}\text { Established hip } \\
\text { fracture registries }\end{array}$ & $\begin{array}{l}\text { Good quality } \\
\text { hip fracture rates }\end{array}$ & $\begin{array}{l}\text { Poor quality } \\
\text { hip fracture rates }\end{array}$ & & & & & & & & & \\
\hline $\begin{array}{l}\text { Healthcare } \\
\text { priority }\end{array}$ & $\begin{array}{l}\text { The presence of a government- } \\
\text { backed healthcare priority }\end{array}$ & $\begin{array}{l}\text { Health priority and } \\
\text { its implementation }\end{array}$ & $\begin{array}{l}\text { Health priority but little } \\
\text { or no implementation }\end{array}$ & Not a health priority & & & & & & & & & \\
\hline $\begin{array}{l}\text { Care } \\
\text { pathway }\end{array}$ & Management in primary care & $\begin{array}{l}\text { OP mainly managed } \\
\text { in primary care }\end{array}$ & $\begin{array}{l}\text { OP mainly managed } \\
\text { by a single specialty }\end{array}$ & $\begin{array}{l}\text { OP mainly managed } \\
\text { by multiple specialties }\end{array}$ & & & & & & & & & \\
\hline $\begin{array}{l}\text { Specialist } \\
\text { training }\end{array}$ & OP an established specialty & Recognized specialty & $\begin{array}{l}\text { Recognized part of } \\
\text { specialty training }\end{array}$ & Neither & & & * & * & * & * & * & * & * \\
\hline $\begin{array}{l}\text { Society } \\
\text { support }\end{array}$ & Patient support societies & $\begin{array}{l}\text { Patient contact } \\
\text { society }\end{array}$ & $\begin{array}{l}\text { Patient support society } \\
\text { with no patient contact }\end{array}$ & $\begin{array}{l}\text { No patient } \\
\text { outreach }\end{array}$ & & & * & * & * & * & * & * & * \\
\hline \multicolumn{14}{|c|}{ Service Provision } \\
\hline Treatment & $\begin{array}{l}\text { Reimbursement and } \\
\text { problems that arise }\end{array}$ & Full reimbursement & $\begin{array}{l}\text { Restricted, } \\
\text { few impediments }\end{array}$ & $\begin{array}{l}\text { Restricted, } \\
\text { major impediments }\end{array}$ & & & & & & & & & \\
\hline $\begin{array}{l}\text { Availability } \\
\text { of DXA }\end{array}$ & $\begin{array}{l}\text { Number of DXA units available } \\
\text { in general population }\end{array}$ & $>18$ per million & 8.4-18 per million & $<8.4$ per million & & & * & * & * & * & * & * & * \\
\hline $\begin{array}{l}\text { Access } \\
\text { to DXA }\end{array}$ & $\begin{array}{l}\text { Reimbursement and } \\
\text { problems that arise }\end{array}$ & Full reimbursement & $\begin{array}{c}\text { Restricted, } \\
\text { few impediments }\end{array}$ & $\begin{array}{l}\text { Restricted, } \\
\text { major impediments }\end{array}$ & & & & & & & & & \\
\hline $\begin{array}{l}\text { Risk } \\
\text { models }\end{array}$ & $\begin{array}{l}\text { Availability of country-specific } \\
\text { risk models and guidance }\end{array}$ & $\begin{array}{l}\text { Model available with } \\
\text { guidance on its use }\end{array}$ & $\begin{array}{l}\text { Model available but no } \\
\text { guidance on its use }\end{array}$ & Model not available & & & * & * & * & * & * & * & * \\
\hline $\begin{array}{l}\text { Guideline } \\
\text { quality }\end{array}$ & $\begin{array}{l}\text { Quality and scope of guidelines } \\
\text { for assessment and treatment }\end{array}$ & $\begin{array}{l}\text { Extensive, high } \\
\text { quality guidelines }\end{array}$ & $\begin{array}{l}\text { Intermediate scope } \\
\text { or quality }\end{array}$ & $\begin{array}{l}\text { Poor scope } \\
\text { or quality }\end{array}$ & & & * & * & * & * & * & * & * \\
\hline $\begin{array}{l}\text { Liaison } \\
\text { services }\end{array}$ & Provision for FLS & $\begin{array}{l}\text { FLS in }>10 \% \text { of } \\
\text { hospitals }\end{array}$ & $\begin{array}{l}\text { FLS in } 1-10 \% \text { of } \\
\text { hospitals }\end{array}$ & No FLS & & & & & & & & & \\
\hline $\begin{array}{l}\text { Quality } \\
\text { indicators }\end{array}$ & $\begin{array}{l}\text { Presence and use of } \\
\text { quality indicators }\end{array}$ & $\begin{array}{l}\text { Systems and } \\
\text { performance criteria }\end{array}$ & $\begin{array}{l}\text { Systems } \\
\text { but no audit }\end{array}$ & $\begin{array}{l}\text { No systems } \\
\text { in place }\end{array}$ & & & * & * & * & * & * & * & * \\
\hline \multicolumn{14}{|c|}{ Service Uptake } \\
\hline $\begin{array}{l}\text { Risk } \\
\text { models }\end{array}$ & $\begin{array}{l}\text { Annual FRAX calculations } \\
\text { (general population, } \geq 50 \mathrm{yrs} \text { ) }\end{array}$ & $>1,200$ per million & $320-1,200$ per million & $<320$ per million & & & * & * & * & * & * & * & * \\
\hline $\begin{array}{l}\text { Treatment } \\
\text { gap }\end{array}$ & $\begin{array}{l}\text { Proportion of women at high risk } \\
\text { who are untreated }(\geq 50 \mathrm{yrs})\end{array}$ & $<45 \%$ & $45-65 \%$ & $>65 \%$ & $\begin{array}{c}\text { No } \\
\text { data }\end{array}$ & & * & * & * & * & * & * & * \\
\hline $\begin{array}{l}\text { Waiting } \\
\text { time }\end{array}$ & $\begin{array}{l}\text { Average waiting time for } \\
\text { hip surgery }\end{array}$ & $<1$ day & $1-2$ days & $>2$ days & $\begin{array}{c}\text { No } \\
\text { data }\end{array}$ & & & & & & & & \\
\hline
\end{tabular}

Fig. 1 Scorecard for osteoporosis in Canada and seven Canadian provinces, *Not amenable to provincial scoring. Abbreviations: $\mathrm{AB}$ Alberta, BC British Columbia, CAN Canada, DXA dual-energy X-ray absorptiometry, FLS fracture liaison service, FRAX fracture risk assessment tool, NB New Brunswick, NL Newfoundland and Labrador, ON Ontario, OP osteoporosis, QC Quebec, SK Saskatchewan, yrs years
Newfoundland were the only provinces that received yellow scores for care pathway. Although general practitioners are the first point of contact in both of these provinces, cases are more frequently devolved to rheumatologists and endocrinologists and are therefore managed primarily by specialists.
Osteoporosis and metabolic bone disease are not recognized as medical specialties by the Royal College of Physicians and Surgeons of Canada, but osteoporosis is a recognized component of endocrinology and rheumatology training (yellow score) [25]. Since the Royal College operates 
Table 1 Number of fractures and predicted population growth in men and women $\geq 50$ years

\begin{tabular}{lclll}
\hline $\begin{array}{l}\text { Country/ } \\
\text { Province }\end{array}$ & $\begin{array}{l}\text { Number of } \\
\text { fractures in } \\
2015[9,21, \\
50]\end{array}$ & $\begin{array}{l}\text { Population at } \\
\text { risk in 2015 } \\
\text { (thousands) } \\
{[22]}\end{array}$ & $\begin{array}{l}\text { Crude } \\
\text { fracture } \\
\text { rate/1000 }\end{array}$ & $\begin{array}{l}\text { Population } \\
\text { growth } \\
2015-2030 \\
{[22,24]}\end{array}$ \\
\hline Canada & 211,968 & 13,363 & 16 & $24 \%$ \\
British & 30,856 & 1866 & 17 & $23 \%$ \\
$\quad$ Columbia & & & & $39 \%$ \\
Alberta & 17,027 & 1271 & 13 & $24 \%$ \\
Saskatchewan & 8510 & 389 & 22 & $26 \%$ \\
Ontario & 76,627 & 5092 & 15 & $19 \%$ \\
Quebec & 53,052 & 3257 & 16 & $19 \%$ \\
New & 5399 & 327 & 17 & $15 \%$ \\
$\quad$ Brunswick & & & & $18 \%$ \\
Newfoundland & 3654 & 225 & 16 & $18 \%$ \\
\hline
\end{tabular}

${ }^{a}$ Includes hip, vertebral, wrist, pelvic, and other fractures

Sources: Tarride et al. (2012) [9], Osteoporosis Canada (2013) [21], Statistics Canada (2019) [22], Statistics Canada (2019) [24], and Burge et al. (2007) [50]

${ }^{\mathrm{b}}$ Historically, Alberta has one of the highest population growth rates in Canada. Between 1972 and 2009, Alberta achieved an average annual population growth that was almost double the Canadian average [51]

as a national body with uniform regulations country-wide, the individual provinces were not scored.

Canada has two national societies that support osteoporosis initiatives-Osteoporosis Canada and the Canadian Menopause Society. Osteoporosis Canada is the main support society and was the focus of our scoring. Osteoporosis Canada organizes patient support groups and has a patient network to connect people living with osteoporosis. We classified Osteoporosis Canada as a patient contact society, which earned Canada a green score. However, Osteoporosis Canada also sponsors osteoporosis guidelines and regularly engages with physicians through its scientific advisory council.

\section{Service provision}

Each Canadian province/territory has its own heath care system and public drug formulary. Consequently, Canada's yellow score for treatment reimbursement was based on the most frequent score among the selected provinces. British Columbia received a red score, while all other provinces received yellow scores. Oral bisphosphonates are easily accessible with few restrictions and fully reimbursed in all the studied provinces except British Columbia, where patients are first required to have a clinically- or radiographically-documented osteoporotic fracture. All seven provinces restrict access to denosumab and zoledronic acid, despite these treatments being recommended as first-line options in the Canadian clinical practice guidelines [27]. In most provinces, the patient must first fail, be intolerant to, or have a contraindication for oral bisphosphonates to qualify for these treatments. Zoledronic acid is not on the provincial formulary for Newfoundland, but it is accessible through hospital formularies with restricted access. Quebec and New Brunswick are the only provinces that have unrestricted access to raloxifene as a first-line treatment. There was unanimous consensus among the experts that these reimbursement policies interfere with what physicians would otherwise prescribe to patients.

In 2003, an estimated 16.3 DXA machines were available per million of the population in Canada (yellow score) [28]. Whether this estimate is still valid today is uncertain. Access to DXA scans varies by province; therefore, Canada received a yellow score overall. Most patients can receive a DXA scan within 1 or 2 weeks, but those living in less populated or remote areas may have to wait up to a month. DXA scans are fully reimbursed in Alberta, Ontario, Quebec, New Brunswick, and Newfoundland (green scores) but not reimbursed in Saskatchewan (red score). Tight reimbursement restrictions exist in British Columbia, where BMD testing is not indicated unless patients are aged $>65$ years at a moderate risk of fracture (10-20\% 10-year risk) and results are likely to alter patient care (red score). Additionally, DXA is not indicated in British Columbia for confirmation of osteoporosis after the patient has sustained a fragility fracture.

The availability of fracture risk assessment models was only scored at the national level. Canada scored green because there is a country-specific FRAX model available [29]. An additional risk assessment tool, CAROC, is also available to Canadian physicians. Both tools are recommended by the national osteoporosis guidelines [27].

We selected the 2010 national guidelines by Osteoporosis Canada for scoring because they are the mainstay of clinical practice. The guidelines scored as high quality ( $9 / 10$ points, green) because they were informed by a systematic search, the recommendations were graded, multiple stakeholders were consulted during development, they underwent external review, the writing group had editorial independence, and an update is anticipated in 2020.

The FLS registry reported 46 FLS programs across Canada as of June 2019, which translates to $6.6 \%$ of Canadian hospitals (yellow score) [31-33]. Thirty centers were located in Ontario, where $21 \%$ of hospitals were estimated to have FLS programs (green score). British Columbia, Alberta, and Quebec had 1, 8, and 4 FLS programs, respectively (yellow scores). There were no FLS programs in Saskatchewan, New Brunswick, or Newfoundland (red scores) [31]. However, these numbers may underestimate the total number of FLS programs in Canada because the registry only accounts for hospitals that have submitted to Osteoporosis Canada and that have met specific FLS criteria [31]. 
Canada scored green for the quality indicators element because Osteoporosis Canada periodically audits FLS programs across the country. Results from the most recent audit were published in 2018 [34]. The audit used three core indicators to provide an overview of the treatment provided to patients enrolled in a Canadian FLS: (1) identification of patients presenting to the specific FLS setting, (2) investigation (i.e., the proportion of FLS patients who complete their first fracture risk assessment within three months of enrollment), and (3) initiation of effective osteoporosis treatment within six months of enrollment [34].

\section{Service uptake}

Canada scored green for FRAX uptake. According to Kanis et al., 7668 FRAX calculations per million of the general population aged $\geq 50$ years were performed in Canada during 2013 [35]. This value may be overestimated because the sample did not take repeat calculations into account, or calculations performed for research purposes.

Publications that report the proportion of osteoporosis patients who receive treatment tend to focus on specific subgroups of patients that are not representative of the general population, such as FLS patients who have already sustained a fracture and likely have higher treatment rates than the general population. Furthermore, there are two tools (FRAX and CAROC) recommended by Canadian clinical practice guidelines for categorizing risk and the intervention thresholds at which patients should receive treatment. Despite a high level of concordance between the two, the definition of "high risk" varies in some cases and can lead to discrepancies in terms of who should be treated [37]. Therefore, the treatment gap element was scored as black to indicate a lack of consistent data.

Canada received a green score for wait times because 50\% of Canadians receive surgery within $22 \mathrm{~h}$ of sustaining a hip fracture [36]. Saskatchewan had the longest mean wait times (33 h), followed by British Columbia ( $27 \mathrm{~h}$ ), and Ontario (24 h), earning them yellow scores. The other provinces scored green, with Alberta having the shortest wait time (17 h). CIHI did not report data for Quebec (black score). The thresholds established in SCOPE require the majority of patients to receive surgery within $24 \mathrm{~h}$ to achieve a green score. However, the benchmark set by CIHI is for patients to receive surgery within $48 \mathrm{~h}$ and upwards of $79 \%$ of patients in the selected provinces met this benchmark $[13,36]$.

\section{Discussion}

In general, Canada was assigned a mix of yellow and green scores for key indicators of the burden of osteoporosis and its management. The single red, or high risk, score was assigned because osteoporosis is not a national health priority in
Canada. Another area of concern (yellow score) was the discrepancy between what the national guidelines recommend for treatment of osteoporosis and the public reimbursement policies. The national guidelines state that several treatments - including alendronate, risedronate, raloxifene, zoledronic acid, and denosumab - are suitable for first-line therapy for prevention of fracture, but not all of these options are reflected as such in the provincial formularies. This restrictive reimbursement environment poses a major barrier that hinders physician selection and patient access to guidelinerecommended treatments.

Canada's strengths (green scores) lie in its high-quality guidelines for the diagnosis and treatment of osteoporosis, the availability and uptake of risk assessment tools (FRAX and CAROC), and lower wait times for hip fracture surgery. However, certain green scores should be interpreted with caution. The scoring thresholds indicate where Canada scores in relation to the EU countries; therefore, a green score does not necessarily represent the optimal standard of care. For example, Canada scored green on the care pathway element because family physicians are the primary point of contact for osteoporosis care, but the existing care pathway may still be failing patients. According to experts, osteoporosis is not a priority for family physicians because rarely do they (or their patients) see the direct link between a fragility fracture and osteoporosis, or osteoporosis and an increased risk of mortality. Diseases that are more commonly perceived as life-threatening, such as breast cancer and cardiovascular diseases, are prioritized instead [41]. Treating patients with osteoporosis medications has also received backlash because of the overemphasized rare associations with atypical fractures [42-45] and osteonecrosis of the jaw [45-47]. The negative publicity and misinformation have had a lasting impact on public perception, and many patients and physicians now have the false impression that osteoporosis medications cause more fractures than they prevent. This has left family physicians confused regarding the best course of action.

Canada also scored well on the quality indicators element for systematically collecting data on the quality of care offered to osteoporosis patients, but the results of the FLS audit demonstrate that underdiagnosis and undertreatment persist within the FLS framework [34]. According to the audit, only 57\% of patients present to the correct setting, $89 \%$ complete a fracture risk assessment within 3 months, and $49 \%$ are on first-line osteoporosis medication within 6 months [34]. The results show that FLS programs have positively impacted the treatment of osteoporosis, but there is still room for improvement [34].

The national score allows us to compare Canada to the 27 countries of the EU assessed in SCOPE. When compared to the EU scorecard, the state of osteoporosis in Canada appears to resemble countries such as the Netherlands, Finland, and the UK, which also have a mixture of predominately green 
and yellow scores. However, unlike Canada, all three of these European countries have established national hip fracture registries. The UK National Hip Fracture Database tracks not only hip fracture incidence but also all aspects of care provided to hip fracture patients [48]. Implementation of a similar database in Canada could improve the documentation of fractures and inform better quality care.

In some cases, the national scores mask regional variations in care. Although Canada received a green score for the society support element, Osteoporosis Canada focuses its efforts primarily in Ontario where it receives most of its funding [49]. Moreover, the percentage of hospitals with FLS programs varied from 0\% in Saskatchewan, New Brunswick, and Newfoundland to a maximum of $21 \%$ in Ontario [31, 32]. Government action is required to increase the equitable distribution of FLS programs across provinces.

Overall, Ontario and Alberta appeared to be at the lowest risk, with the greatest number of elements scored green. Of the provinces assessed, Ontario and Alberta were the only two with formal action plans, and combined, they contained $83 \%$ of the country's FLS programs [31]. In contrast, out of the ten elements that were scored at the provincial level, six or more were yellow or red for the remaining provinces, denoting less than optimal approaches to the management of osteoporosis.

Similar results were seen in the 2008 National Report Card [12]. Ontario and Alberta received the highest grades (B) for uptake of DXA testing, whereas Saskatchewan received an F or failing grade. Ontario and Quebec received the highest grades for access to osteoporosis medications in the 2008 report card. British Columbia received a C- grade, which is consistent with the red score it received for the treatment reimbursement element of our scorecard. This suggests that some care gaps that were identified over a decade ago persist today and warrant renewed attention.

Our scorecard also functions as a benchmark against which we can measure future progress in the management of osteoporosis in Canada. New national osteoporosis guidelines are expected within the next year, so we anticipate that within the next 5 years we will see the effects of the updated recommendations being implemented. At that point, it may be appropriate to reassess the scorecard elements to analyze the impact of the guidelines on the management of osteoporosis in Canada.

Our study has several strengths. It is based on a published peer-reviewed template that was used to score the 27 countries of the EU, and has been adapted recently to score four Latin American countries [13, 14]. Therefore, the current format allows for direct comparison to countries that have been previously assessed. The scorecard also analyzes a greater breadth of osteoporosis indicators than past Canadian reports. We expanded the scoring to the provinces to explore regional differences that may be masked by the national score. Additionally, we informed our scorecard with an extensive evidence base. Our literature search allowed us to capture the most recent data available, and the interviews with clinical experts provided insight into areas of care that are not described in the literature.

Our study has some limitations. We were only able to solicit expert feedback from seven of the ten provinces and none of the territories in Canada, partly due to the small number of osteoporosis experts in some regions. Whether our convenience sample accurately reflects disparities in health provision and disease burden across all provinces/territories remains to be determined. Furthermore, some of the national scores (e.g., treatment reimbursement and DXA access) are based on the average distribution of provincial scores. It is possible that the inclusion of other provinces and territories would have an impact on the results for Canada. We also interviewed a single osteoporosis expert per province. We acknowledge that the experts' opinions may not be reflective of all physicians in their respective provinces and that elements informed strictly by expert opinion may be subject to bias. We assumed that the European scoring thresholds from SCOPE were generalizable to Canada. As previously mentioned, green scores do not necessarily represent optimal care and should be interpreted accordingly. Finally, there were limitations due to data availability and uncertainty, which forced us to occasionally rely on pre-2010 data or score elements black.

The black scores in our scorecard highlight the need for additional research. It would be beneficial to understand what proportion of the general population is high-risk and to better characterize the treatment gap. More research is also needed for the provinces and territories that we did not analyze in this study. Lastly, it would be beneficial to compare the scores across provinces with the clinical outcomes in each province to understand whether the two are correlated and to further validate our scorecard.

\section{Conclusion}

Our osteoporosis scorecard shows that Canada performs moderately well at the national level on the key indicators of the burden and management of osteoporosis, but inequities in care exist across provinces. Ontario and Alberta are at the forefront of osteoporosis care, while British Columbia has a restrictive reimbursement environment that limits access to DXA screening and treatment. Saskatchewan also has limited access to DXA screening and, along with New Brunswick, and Newfoundland, no FLS programs. Canada would benefit from the creation of formal government action plans to support osteoporosis education and awareness, the establishment of prospective fracture registries to monitor patient care, a restructuring of reimbursement policies to align with clinical practice guidelines, and the increased distribution of FLS programs to less populous provinces. Additional research should 
also be conducted to estimate the treatment gap in Canada and to determine the proportion of Canadians with a high risk of sustaining an osteoporotic fracture. As progress is made, this scorecard can serve as a benchmark to measure advancements in osteoporosis management.

Acknowledgments We are grateful for the insightful contributions of all the osteoporosis experts who participated in this study. We also wish to thank Becky Skidmore for conducting our searches for the systematic review and Ana Lüdke for her contributions to the literature review.

Funding information This study was funded by Amgen Inc. EVERSANA received financial support from Amgen for the conduct of this study. LS is an employee of and owns stock in Amgen. NB is an employee of Amgen. CD and RKM are employees of EVERSANA. CC is an employee and shareholder of EVERSANA. EVERSANA consults for various pharmaceutical, medical device, and biotech companies.

\section{Compliance with ethical standards}

Conflicts of interest DLK received research grants, consulting honoraria, and/or speaking honoraria from Amgen, Pfizer, Radius, and Eli Lily. JPB received grants/research support from Amgen, Mereo Biopharma, Radius Health, and Servier; consultant for Amgen; and speakers' bureau for Amgen, Janssen, and Orimed. JDA is a consultant, speaker, and clinical trialist for Amgen. AGJ and CSK received consulting fees from Amgen.

Open Access This article is licensed under a Creative Commons Attribution-NonCommercial 4.0 International License, which permits any non-commercial use, sharing, adaptation, distribution and reproduction in any medium or format, as long as you give appropriate credit to the original author(s) and the source, provide a link to the Creative Commons licence, and indicate if changes were made. The images or other third party material in this article are included in the article's Creative Commons licence, unless indicated otherwise in a credit line to the material. If material is not included in the article's Creative Commons licence and your intended use is not permitted by statutory regulation or exceeds the permitted use, you will need to obtain permission directly from the copyright holder. To view a copy of this licence, visit http://creativecommons.org/licenses/by-nc/4.0/.

\section{References}

1. International Osteoporosis Foundation (2013) Bone care for the postmenopausal woman. https://www.iofbonehealth.org/reports. Accessed 18 October 2019

2. Public Health Agency of Canada (2009) Fast facts from the 2009 Canadian Community Health Survey-osteoporosis rapid response. https://www.canada.ca/en/public-health/services/chronicdiseases/osteoporosis/what-impact-osteoporosis-what-canadiansdoing-maintain-healthy-bones.html. Accessed 28 January 2019

3. Berger C, Goltzman D, Langsetmo L, Joseph L, Jackson S, Kreiger N, Tenenhouse A, Davison KS, Josse RG, Prior JC, Hanley DA, CaMos Research Group (2010) Peak bone mass from longitudinal data: implications for the prevalence, pathophysiology, and diagnosis of osteoporosis. J Bone Miner Res 25(9):1948-1957

4. Statistics Canada (2011) Canada Year Book 2012: Seniors. https:// www150.statcan.gc.ca/n1/en/catalogue/11-402-X. Accessed 18 October 2019
5. Papadimitropoulos EA, Coyte PC, Josse RG, Greenwood CE (1997) Current and projected rates of hip fracture in Canada. CMAJ 157(10):1357-1363

6. Nikitovic M, Wodchis WP, Krahn MD, Cadarette SM (2013) Direct health-care costs attributed to hip fractures among seniors: a matched cohort study. Osteoporos Int 24(2):659-669

7. Pincus D, Ravi B, Wasserstein D, Huang A, Paterson JM, Nathens AB, Kreder HJ, Jenkinson RJ, Wodchis WP (2017) Association between wait time and 30-day mortality in adults undergoing hip fracture surgery. JAMA 318(20):1994-2003

8. Langsetmo L, Goltzman D, Kovacs CS, Adachi JD, Hanley DA, Kreiger N, Josse R, Papaioannou A, Olszynski WP, Jamal SA (2009) Repeat low-trauma fractures occur frequently among men and women who have osteopenic BMD. J Bone Miner Res 24(9): $1515-1522$

9. Tarride JE, Hopkins RB, Leslie WD, Morin S, Adachi JD, Papaioannou A, Bessette L, Brown JP, Goeree R (2012) The burden of illness of osteoporosis in Canada. Osteoporos Int 23(11): 2591-2600

10. Hopkins RB, Burke N, Von Keyserlingk C, Leslie WD, Morin SN, Adachi JD, Papaioannou A, Bessette L, Brown JP, Pericleous L, Tarride J (2016) The current economic burden of illness of osteoporosis in Canada. Osteoporos Int 27(10):3023-3032

11. Osteoporosis Canada (2011) Towards a Fracture-Free Future. http://fls.osteoporosis.ca/wp-content/uploads/white-paper-march2011.pdf. Accessed 28 January 2019

12. Osteoporosis Canada (2008) Breaking barriers, Not bones: 2008 National Report Card on Osteoporosis Care. https://osteoporosis. $\mathrm{ca} /$.

13. Kanis JA, Borgström F, Compston J, Dreinhöfer K, Nolte E, Jonsson L, Lems WF, McCloskey EV, Rizzoli R, Stenmark J (2013) SCOPE: a scorecard for osteoporosis in Europe. Arch Osteoporos 8(1-2):144

14. Aziziyeh R, Amin M, Habib M, Perlaza JG, McTavish RK, Lüdke A, Fernandes S, Sripada K, Cameron C (2019) A scorecard for osteoporosis in four Latin American countries: Brazil, Mexico, Colombia, and Argentina. Arch Osteoporos 14(1):69

15. Moher D, Liberati A, Tetzlaff J, Altman DG (2009) Preferred reporting items for systematic reviews and meta-analyses: the PRISMA statement. BMJ 339:b2535

16. Canadian Agency for Drugs and Technologies in Health (2015) Grey matters: a practical tool for searching health-related grey literature. https://www.cadth.ca/resources/finding-evidence/greymatters.

17. Kaltenthaler E, Tappende P, Paisley S, Squires H (2011) NICE DSU technical support document 13: identifying and reviewing evidence to inform the conceptualisation and population of costeffectiveness models. http://nicedsu.org.uk/wp-content/uploads/ 2016/03/TSD-13-model-parameters.pdf.

18. Leslie WD, O'Donnell S, Lagace C, Walsh P, Bancej C, Jean S, Siminoski K, Kaiser S, Kendler DL, Jaglal S (2010) Populationbased Canadian hip fracture rates with international comparisons. Osteoporos Int 21(8):1317-1322

19. Leslie WD, Lix LM, Langsetmo L, Berger C, Goltzman D, Hanley DA, Adachi JD, Johansson H, Oden A, McCloskey E, Kanis JA (2011) Construction of a FRAX model for the assessment of fracture probability in Canada and implications for treatment. Osteoporos Int 22(3):817-827

20. Kanis JA, Odén A, McCloskey EV, Johansson H, Wahl DA, Cooper C, on behalf of the IOF Working Group on Epidemiology and Quality of Life (2012) A systematic review of hip fracture incidence and probability of fracture worldwide. Osteoporos Int 23 (9):2239-2256

21. Osteoporosis Canada (2013) Make the FIRST break the LAST with Fracture Liaison Services Appendix B: fracture incidence and costs 
by province. http://www.osteoporosis.ca/wp-content/uploads/FLSTOOLKIT.pdf.

22. Statistics Canada (2019) Table 17-10-0005-01 Population estimates on July 1 st, by age and sex. https://www150.statcan.gc.ca/t1/tbl1/ en/tv.action?pid=1710000501. Accessed 17 June 2019

23. Hopkins RB, Pullenayegum E, Goeree R, Adachi JD, Papaioannou A, Leslie WD, Tarride JE, Thabane L (2012) Estimation of the lifetime risk of hip fracture for women and men in Canada. Osteoporos Int 23(3):921-927

24. Statistics Canada (2019) Table 17-10-0057-01 Projected population, by projection scenario, age and sex, as of July 1 (x 1,000$)$. https://www 150. statcan.gc.ca/t1/tb11/en/tv.action?pid= 1710005701 Accessed 17 June 2019

25. Royal College of Physicians and Surgeons of Canada (2019) Royal College of Physicians and Surgeons of Canada. http://www. royalcollege.ca/rcsite/home-e.

26. International Osteoporosis Foundation (2017) National Societies. https://www.iofbonehealth.org/societies-country-index-view/all. Accessed 6 December 2019

27. Papaioannou A, Morin S, Cheung AM, Atkinson S, Brown JP, Feldman S, Hanley DA, Hodsman A, Jamal SA, Kaiser SM, Kvern B, Siminoski K, Leslie WD, Scientific Advisory Council of Osteoporosis Canada (2010) 2010 clinical practice guidelines for the diagnosis and management of osteoporosis in Canada: summary. CMAJ 182 (17):1864-1873

28. Kanis JA, Johnell O (2005) Requirements for DXA for the management of osteoporosis in Europe. Osteoporos Int 16(3):229-238

29. Centre for Metabolic Bone Diseases University of Sheffield (2018) FRAX: Fracture Risk Assessment Tool. https://www.sheffield.ac. uk/FRAX/.

30. The AGREE Next Steps Consortium (2009) Appraisal of Guidelines for REsearch \& Evaluation II. https://www.agreetrust. org/wp-content/uploads/2013/10/AGREE-II-Users-Manual-and23-item-Instrument 2009 UPDATE 2013.pdf

31. Osteoporosis Canada (2019) Canadian FLS Registry. https://fls. osteoporosis.ca/canadian-fls-registry/. Accessed 9 October 2019

32. Canadian Institute for Health Information (2018) Quick StatsCMDB hospital beds staffed and in operation, 2017-2018. https:// www.cihi.ca/en/quick-stats. Accessed 30 July 2019

33. Index Santé - Le répertoire santé du Québec (2019) Répertoire des hôpitaux au Québec. https://www.indexsante.ca/.

34. Osteoporosis Canada (2018) Report from Osteoporosis Canada's first national FLS audit: leading FLS improvement in Canada. http://fls.osteoporosis.ca/wp-content/uploads/Report-fromOsteoporosis-Canadas-first-national-FLS-audit.pdf.

35. Kanis JA, Johansson H, Oden A, Cooper C, McCloskey EV (2014) Worldwide uptake of FRAX. Arch Osteoporos 9:166

36. Canadian Institute for Health Information (2017) Patients receiving treatment within the benchmark for hip fracture repair. http:// waittimes.cihi.ca/procedure/fracture\#year. Accessed 28 January 2019

37. Leslie WD, Majumdar SR, Lix LM, Josse RG, Johansson H, Oden A, McCloskey EV, Kanis JA (2016) Direct comparison of FRAX(R) and a simplified fracture risk assessment tool in routine clinical practice: a registry-based cohort study. Osteoporos Int 27(9):2689-2695

38. Ferrari R (2015) Prevalence of osteoporosis in men aged 65-75 in a primary care setting. A practice audit after application of the
Canadian 2010 guidelines for osteoporosis screening. Clin Rheumatol 34(3):523-527

39. Canadian Institute for Health Information (2019) Discharge Abstract Database metadata (DAD). https://www.cihi.ca/en/ discharge-abstract-database-metadata.

40. Ministry of Health and Long-Term Care, Osteoporosis Canada, Ontario College of Family Physicians, McMaster University, Women's College Hospital, GERAS Centre for Aging Research, St. Michael's Hospital (2019) Ontario Osteoporosis Strategy. https://www.osteostrategy.on.ca/.

41. Proverbs-Singh TA, Studenski S, Cauley J, Perera S, Faulkner K, Hillier T (2007) AGS 2007 Annual Scientific Meeting Abstract P28. Which is more fatal, hip fracture or breast cancer? Survival after hip fracture and breast cancer: a comparison using the SOF database. J Am Geriatr Soc 55(s1):s10-s11

42. Odvina CV, Zerwekh JE, Rao DS, Maalouf N, Gottschalk FA, Pak CY (2005) Severely suppressed bone turnover: a potential complication of alendronate therapy. J Clin Endocrinol Metab 90(3): 1294-1301

43. Isaacs JD, Shidiak L, Harris IA, Szomor ZL (2010) Femoral insufficiency fractures associated with prolonged bisphosphonate therapy. Clin Orthop Relat Res 468(12):3384-3392

44. Girgis CM, Seibel MJ (2011) Atypical femur fractures: a review of the evidence and its implication to clinical practice. Ther Adv Musculoskelet Dis 3(6):301-314

45. Brown JP, Morin S, Leslie W, Papaioannou A, Cheung AM, Davison KS, Goltzman D, Hanley DA, Hodsman A, Josse R, Jovaisas A, Juby A, Kaiser S, Karaplis A, Kendler D, Khan A, Ngui D, Olszynski W, Ste-Marie LG, Adachi J (2014) Bisphosphonates for treatment of osteoporosis: expected benefits, potential harms, and drug holidays. Can Fam Physician 60(4):324333

46. Mavrokokki T, Cheng A, Stein B, Goss A (2007) Nature and frequency of bisphosphonate-associated osteonecrosis of the jaws in Australia. J Oral Maxillofac Surg 65(3):415-423

47. Lo JC, O'Ryan FS, Gordon NP, Yang J, Hui RL, Martin D, Hutchinson M, Lathon PV, Sanchez G, Silver P, Chandra M, McCloskey CA, Staffa JA, Willy M, Selby JV, Go AS (2010) Prevalence of osteonecrosis of the jaw in patients with oral bisphosphonate exposure. J Oral Maxillofac Surg 68(2):243-253

48. Royal College of Physicians (2019) The National Hip Fracture Database. https://www.nhfd.co.uk/. Accessed 25 October 2019

49. Osteoporosis Canada (2018) Impact report 2017-2018. https:// osteoporosis.ca/wp-content/uploads/EN-Osteo-Impact-ReportF2017-2018.pdf.

50. Burge R, Dawson-Hughes B, Solomon DH, Wong JB, King A, Tosteson A (2007) Incidence and economic burden of osteoporosis-related fractures in the United States, 2005-2025. J Bone Miner Res 22(3):465-475

51. Government of Alberta (2010) Alberta population projections by Census Division, 2010-2050. https://open.alberta.ca/publications/ 5336155. Accessed 6 December 2019

Publisher's note Springer Nature remains neutral with regard to jurisdictional claims in published maps and institutional affiliations. 